\title{
HDlive Silhouette for Antenatal Diagnosis of Uterine Synechia
}

\author{
${ }^{1}$ Ayumi Mori, ${ }^{2}$ Megumi Ito, ${ }^{3}$ Nobuhiro Mori, ${ }^{4}$ Kenji Kanenishi, ${ }^{5}$ Hirokazu Tanaka, ${ }^{6}$ Toshiyuki Hata
}

\begin{abstract}
We present our experience of using HDlive studio and HDlive silhouette to diagnose uterine synechia at 18 weeks and 2 days of gestation. Two-dimensional (2D) sonography showed a narrow, transverse uterine synechia in the amniotic cavity. 2D color Doppler revealed arterial blood flow consistent with the maternal heart rate in the uterine synechia. HDlive silhouette clearly demonstrated a transverse, bridging uterine synechia in front of the fetal head, and fetal arm and leg behind the placenta. Magnetic resonance imaging (MRI) confirmed the oblique horizontal band-like synechia at 31 weeks of gestation. HDlive silhouette and HDlive studio provided a novel visual depiction of uterine synechia and allowed us to demonstrate the spatial relationships among the uterine synechia, placenta, umbilical cord, and fetus in the amniotic cavity.
\end{abstract}

Keywords: Antenatal diagnosis, HDlive silhouette, HDlive studio, Pregnancy, Uterine synechia.

How to cite this article: Mori A, Ito M, Mori N, Kanenishi K, Tanaka H, Hata T. HDlive Silhouette for Antenatal Diagnosis of Uterine Synechia. Donald School J Ultrasound Obstet Gynecol 2018;12(4):249-251.

Source of support: Nil

Conflict of interest: None

\section{INTRODUCTION}

Three-dimensional (3D) ultrasound clarifies the spatial relationships of uterine synechia in the amniotic cavity during pregnancy, which is not achievable with $2 \mathrm{D}$ sonography. ${ }^{1,2}$ Moreover, HDlive provides more realistic images of uterine synechia, compared with conventional 3D ultrasound. ${ }^{3,4}$ HDlive silhouette provides vitreous-like clarity of the fetus and placenta and allows the examiner to observe structures present behind the directly visualized structure, making it more advantageous than conventional 3D ultrasound and HDlive. ${ }^{5-9}$ Here, we present our experience of using HDlive studio and HDlive silhouette to diagnose uterine synechia.

\footnotetext{
${ }^{1}$ Resident, ${ }^{2}$ Assistant Professor, ${ }^{3}$ Lecturer, ${ }^{4,5}$ Associate Professor, ${ }^{6}$ Professor and Chairman

${ }^{1-6}$ Department of Perinatology and Gynecology, Kagawa University Graduate School of Medicine, Japan
}

Corresponding Author: Toshiyuki Hata, Professor and Chairman, Department of Perinatology and Gynecology, Kagawa University Graduate School of Medicine, Japan, Phone: +81(0)87-891-2174, e-mail: toshi28@med.kagawa-u.ac.jp

\section{CASE REPORT}

A 37-year-old pregnant Japanese woman, gravida 5, para 0 , was referred to our ultrasound clinic due to suspected amniotic band syndrome at 18 weeks and 2 days of gestation. 2D sonography showed a narrow, transverse uterine synechia in the amniotic cavity (Fig. 1). 2D color Doppler revealed an arterial blood flow consistent with the maternal heart rate in the uterine synechia. HDlive studio showed a transverse uterine synechia in front of the fetal head in the amniotic cavity (Fig. 2A). HDlive silhouette demonstrated a transverse, bridging uterine synechia in front of the fetal head (Fig. 2B), and fetal arm and leg behind the placenta (Fig. 2C). MRI confirmed the oblique horizontal band-like synechia at 31 weeks of gestation (Fig. 3).

Elective cesarean section was performed at 38 weeks and 3 days of gestation because of the difficulty of vaginal delivery due to fetal malpresentation, and a male infant weighing 2,936 g was delivered with an umbilical artery $\mathrm{pH}$ of 7.324, and Apgar score of 8/9 at 1 minute and 5 minutes, respectively. The transverse, bridging synechia was confirmed during the operation (Fig. 4) and was resected. The mother and neonate followed favorable courses after delivery.

\section{DISCUSSION}

The incidence of uterine synechiae is $0.45 \%$, and they are correlated with a significant increase in the risk of preterm

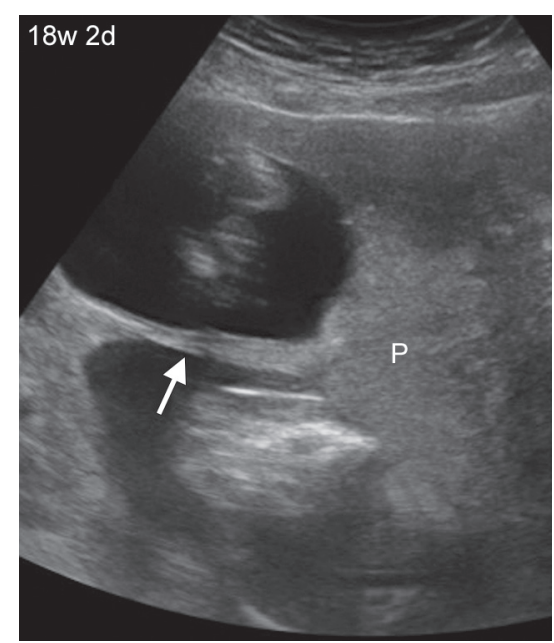

Fig. 1: Two-dimensional sonographic image of a narrow, transverse uterine synechia (arrow) at 18 weeks and 2 days of gestation. P, placenta. 

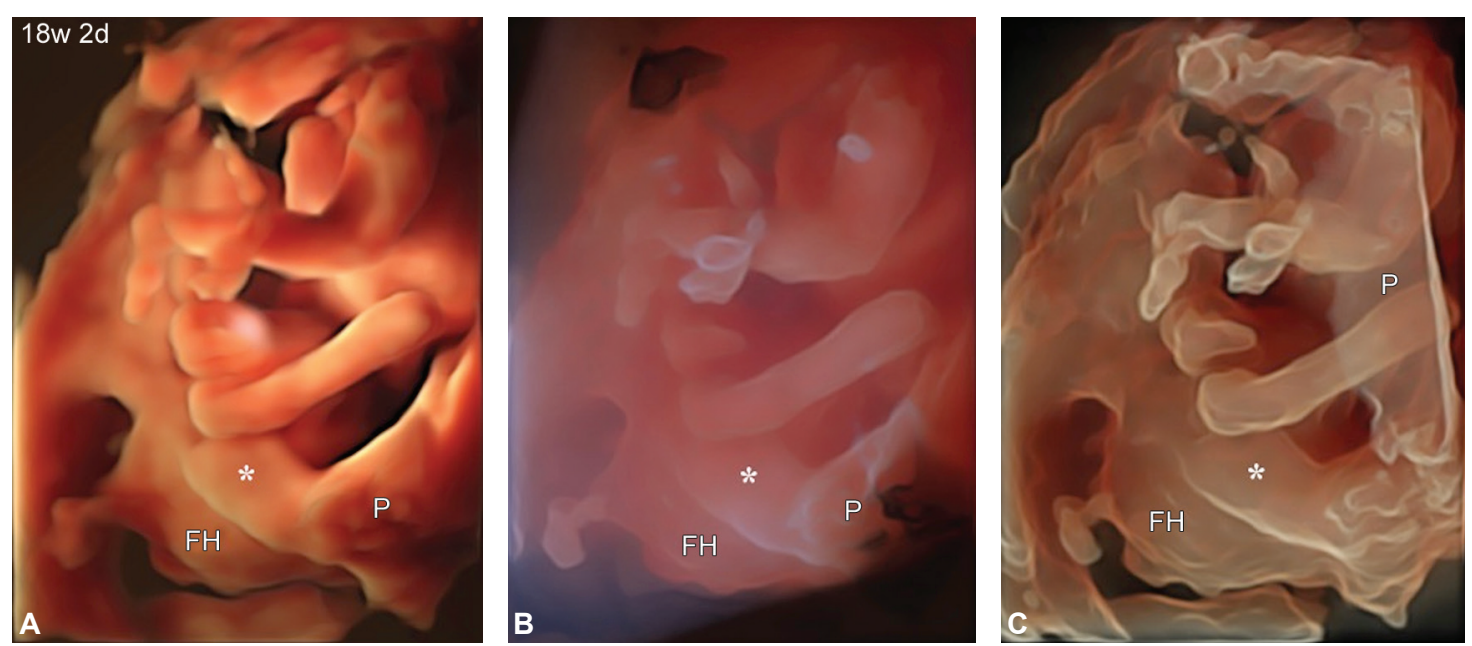

Figs 2A to C: HDlive studio and HDlive silhouette images of uterine synechia $\left({ }^{*}\right)$ at 18 weeks and 2 days of gestation. (A) HDlive studio shows a transverse uterine synechia in front of the fetal head in the amniotic cavity; (B) HDlive silhouette demonstrates a transverse, bridging uterine synechia in front of the fetal head; and (C) fetal arm and leg behind the placenta. $\mathrm{FH}$, fetal head; $\mathrm{P}$, placenta

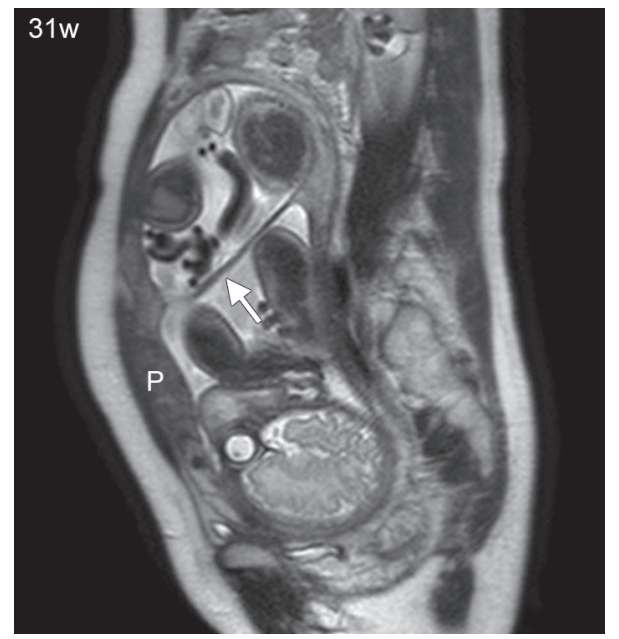

Fig. 3: Sagittal T2-weighted MR image of uterine synechia at 31 weeks of gestation. MRI confirms the oblique horizontal band-like synechia (arrow). P, placenta

premature rupture of membranes, placental abruption, and cesarean delivery due to malpresentation. ${ }^{10}$ Therefore, a precise diagnosis of uterine synechia is mandatory for comprehensive perinatal management of a patient.

The placental shelf rarely persists to mid-gestation, but never to the third trimester. ${ }^{11,12}$ It is not attached to any fetal parts, and there is no fetal abnormality. 3D ultrasound and HDlive clearly show its characteristic features such as smooth, round, and thick free edges., ${ }^{3,12}$ In utero, fetal malformations with fibrous bands that wrap around parts of the fetus are collectively called amniotic band syndrome. ${ }^{13}$ Using 3D ultrasound and HDlive, the continuity, extension, and motion of amniotic bands could be more easily clarified, and spatial relationships between the amniotic bands and fetus could be more readily understood compared with using conventional 2D sonography. ${ }^{14-17}$ During pregnancy, amniotic shelves or sheets are produced by the wrapping of chorioamniotic

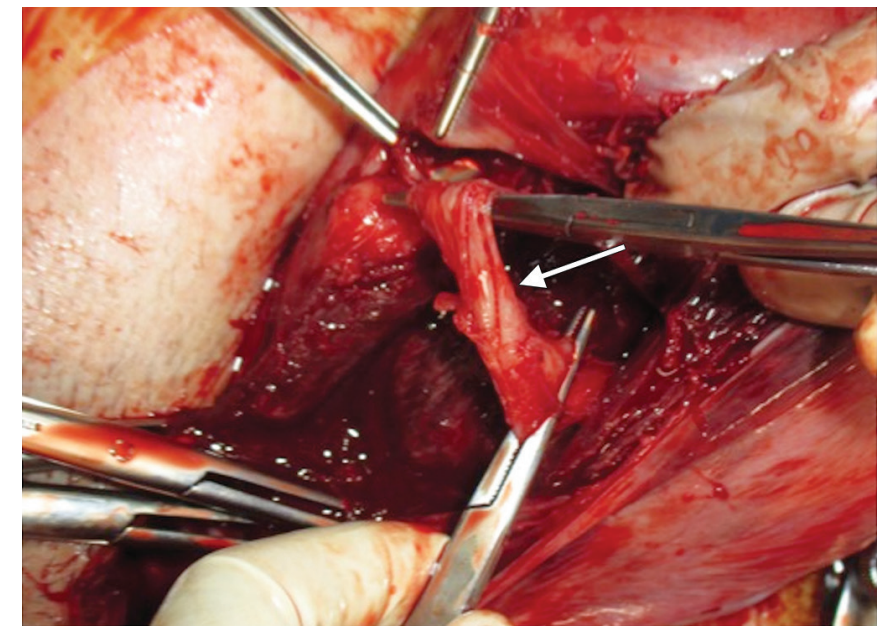

Fig. 4: The transverse, bridging synechia (arrow) confirmed during the operation.

membranes around intrauterine adhesions called as uterine synechiae. ${ }^{10,18,19}$ The use of pulsed Doppler with the maternal heart rate reveals this etiology, and the synechiae can be fully observed using 3D ultrasound and HDlive. ${ }^{1-4}$ Moreover, those modalities enable us to realize the spatial relationships among the uterine synechia, placenta, umbilical cord, and fetus. In the present case, HDlive silhouette demonstrated a transverse, bridging uterine synechia in front of the fetal head, and fetal arm and leg behind the placenta. Therefore, this technique provides holography-like information on overlapping structures in the amniotic cavity.

\section{REFERENCES}

1. Bäumler M, Faure JM, Counter A, et al. Prenatal 3D ultrasound and MRI assessment of horizontal uterine synechia. Prenata Diagn 2008;28:874-875.

2. Sato M, Kanenishi K, Ito M, et al. Antenatal 3-D sonographic features of uterine synechia. J Obstet Gynecol Res 2013;39:395-398. 
3. Hata T, Tenkumo C, Sato M, et al. Three-dimensional HDlive rendered images of intrauterine abnormalities during pregnancy. J Med Ultrasonics 2012;40:179-180.

4. Mashima M, Tanaka H, Ishibashi M, et al. HDlive imaging of vertical, bridging uterine synechia during pregnancy. J Med Ultrasonics 2014;41:521-524.

5. AboEllail MAM, Hanaoka U, Numoto A, et al. HDlive imaging of a giant fetal hemangioma. J Ultrasound Med 2015;34:2313-2318.

6. AboEllail MAM, Kanenishi K, Mori N, et al. HDlive image of circumvallate placenta. Ultrasound Obstet Gynecol 2015; 46: 513-514.

7. AboEllail MAM, Kanenishi K, Marumo G, et al. Fetal HDlive silhouette mode in clinical practice. Donald School J Ultrasound Obstet Gynecol 2015;9:413-419.

8. AboEllail MAM, Tanaka H, Mori N, et al. HDlive silhouette mode in antenatal diagnosis of jejunal atresia. Ultrasound Obstet Gynecol 2016;48:131-132.

9. Hata T, AboEllail MAM, Sajapala S, et al. HDlive silhouette mode with spatiotemporal correlation for assessment of the fetal heart. J Ultrasound Med 2016;35:1489-1495.

10. Tuuli MG, Shanks A, Bernhard L, et al. Uterine synechiae and pregnancy complications. Obstet Gynecol 2012;119:810-814.

11. Shen O, Golomb E, Lavie O, et al. Placental shelf - a common, typically transient snd benign finding on early second- trimester sonography. Ultrasound Obstet Gynecol 2007;29: 192-194.

12. Hata T, Fujiwara T, Ishibashi M, et al. Antenatal threedimensional sonographic features of placental shelf. J Med Ultrasonics 2012;39:43-44.

13. Seeds JW, Cefalo RC, Herbert WNP. Amniotic band syndrome. Am J Obstet Gynecol 1982;144:243-248.

14. Inubashiri E, Hanaoka U, Kanenishi K, et al. 3D and 4D sonographic imaging of amniotic band syndrome in early pregnancy. J Clin Ultrasound 2008;36:573-575.

15. Hata T, Tanaka H, Noguchi J. 3D/4D sonographic evaluation of amniotic band syndrome in early pregnancy: A supplement to 2D ultrasound. J Obstet Gynaecol Res 2011;37:656-660.

16. Hata T, Hanaoka U, Tenkumo C, et al. Three- and fourdimensional HDlive rendering images of normal and abnormal fetuses: pictorial essay. Arch Gynecol Obstet 2012;286:1431-1435.

17. Hata T, Uketa E, Tenkumo C, et al. Three- and four-dimensional HDlive rendering image of fetal acrania/exencephaly in early pregnancy. J Med Ultrasonics 2013;40:271-273.

18. Brown DL, Felker RE, Emerson DS. Intrauterine shelves in pregnancy: Sonographic observations. Am J Roentgenol 1989;153:821-824.

19. Tan KBL, Tan TYT, Tan JVK, et al. The amniotic sheet: a truly benign condition? Ultrasound Obstet Gynecol 2005;26:639-643. 